\title{
Identification, Pathogenicity, and Fungicide Sensitivity of Ascochyta caulina (Teleomorph: Neocamarosporium calvescens) Associated with Black Stem on Quinoa in China
}

\author{
Hui Yin, Jianbo Zhou, Hong Lv, Nan Qin, Fang Juan Chang, and Xiaojun Zhao ${ }^{\dagger}$ \\ College of Plant Protection, Shanxi Agricultural University, Taiyuan, Shanxi, China
}

\begin{abstract}
Quinoa black stem is a new disease that affects the stems of quinoa plants and is more likely to develop under cool conditions (15 to $25^{\circ} \mathrm{C}, \mathrm{RH}=55 \pm 2 \%$ ). The typical symptoms include the formation of black necrotic lesions on the stem, which can completely wrap around the stem, causing lodging and blanking (development of 'empty' and sterile grain on the panicle). Furthermore, the pycnidia form small round protrusions on the surface of the lesions. Phylogenetic analysis revealed that representative isolates LMHS-3 and LMHS-5 were closely related to Ascochyta caulina (teleomorph: Neocamarosporium calvescens). Comprehensive morphological and molecular characterizations confirmed A. caulina as the pathogen that caused quinoa black stem. A. caulina mainly infected quinoa stems

onset of quinoa black stem was from 15 to $25^{\circ} \mathrm{C}$. When the temperature was increased above $30^{\circ} \mathrm{C}$, the conidial germination of A. caulina became malformed, and when the temperature was decreased below $5^{\circ} \mathrm{C}$, mycelium growth of $A$. caulina became extremely slow; thus, both extreme high and low temperatures affected the pathogenicity of $A$. caulina. Mancozeb and azoxystrobin fungicides were revealed to have had the strongest inhibitory effects on the conidial germination of $A$. caulina, and in some cases caused malformations in conidial germination. Tebuconazole and difenoconazole had the strongest inhibitory effects on A. caulina mycelial growth and less on the effects on the conidial germination. The results of the present study provide a basis for the recognition and management of quinoa black stem.
\end{abstract} and could produce many pycnidia, but it rarely infected quinoa leaves. Pathogenicity testing showed that the most suitable temperature for the
Keywords: quinoa, fungal disease, morphology, conidia, teleomorph
Quinoa (Chenopodium quinoa) is a dicotyledonous annual plant in the family Amaranthaceae (Maughan et al. 2007). It is currently being grown as a new food crop in more than 90 countries across South America, Europe, Oceania, and Asia (Singh et al. 2016), among which Bolivia, Peru, Ecuador, and Chile are the main exporters (Pellegrini et al. 2018). Since 2014, the large-scale cultivation of quinoa has begun in Shanxi, Qinghai, Gansu, and Hebei provinces of China, covering an area of $\sim 3,333$ ha, thus showing an increasing trend in development (Ren et al. 2015).

With quinoa cultivation becoming more widespread, the occurrence of quinoa diseases in China, such as quinoa downy mildew and Cercospora leaf spot, have become increasingly serious and threaten the development of the quinoa industry (Yin et al. 2018, 2019). In 2017, a new disease of quinoa stems was identified in plantations in Jingle, Ningwu, Wutai, and Shanyin counties of Shanxi Province, China. This disease was first observed during the flowering stage of quinoa and the lengths of the lesions were from 0.3 to $1.2 \mathrm{~cm}$. In the early stages of this disease, the lesions appeared pale, and the margins between the lesions and healthy tissue were clear. In the later stages, the main lesions became blackened and were accompanied by numerous small black spots. In severe cases, the plants exhibited lodging, leaf yellowing, leaf shedding, and blanking (development of 'empty' and sterile grains on the panicle). In 2017, we found that disease incidence was $\sim 80 \%$, and the yield was consequently reduced by $\sim 45 \%$ in the quinoa fields where the disease was most severe in Jingle County, Shanxi Province.

${ }^{\dagger}$ Corresponding author: X. J. Zhao, zhaoxiaojun0218@163.com

Funding: This work was supported by The Key Research and Development Program of Shanxi (No. 201903D221014) and Characteristic Industry Research Project of Shanxi Academy of Agricultural Sciences (No. YCX2018D2T02)

The author(s) declare no conflict of interest.

Accepted for publication 19 April 2020.

(C) 2020 The American Phytopathological Society
Similar necrotic lesions on the leaves and stems of Chenopodiaceae plants have also been reported (van der Aa and van Kesteren 1979). Typically, the Ascochyta leaf spot and stem lesions on quinoa caused by Ascochyta hyalospora have light spots of indefinite areas on the leaves, and stem necroses (Boerema et al. 1977; Li et al. 2017). At the later stages of the disease, Ascochyta leaf spots of quinoa become dry and the leaves fall off ( $\mathrm{Li}$ et al. 2017). Black stem disease of quinoa, investigated in this study, mainly results in black necrotic lesions on the stems and rarely on the leaves.

Ascochyta leaf spot and stem necroses on various species of Chenopodiaceae and Atriplex have already spread in Europe and Siberia by A. hyalospora and A. caulina (Boerema et al. 1977, van der Aa and van Kesteren 1979). van der Aa and van Kesteren (1979) reported that A. caulina infected eight species of Atriplex (A. hortense, A. lacinata, A. littoralis, A. nitens, A. patula, A. hastata, A. hortensis, and A. oblongifolium) and eight species of Chenopodium (C. album, C. bonus-henricus, C. glaucum, C. hybridum, C. murale, C. viride, C. suecicum, and C. vulvaria). Boerema et al. (1977), de Gruyter et al. (2009), and van der Aa and van Kesteren (1979) reported that A. caulina and A. hyalospora had similar morphologies. There are multiple synonyms on Chenopodium plants caused by these species that are similar (van der Aa and van Kesteren 1979), so the two species are often confused.

In 2003, Dřímalková detected $A$. caulina in quinoa seeds from the Czech Republic, but they did not report that $A$. caulina could infect quinoa (Dřímalková 2003). Presently, there are no definitive reports that $A$. caulina can infect quinoa. There is confusion in the research concerning Ascochyta leaf spot of quinoa. The confusion stems from the inaccurate classification of the pathogens and a lack of previous systematic research. The sexual stage of A. caulina is called Pleospora calvescens (Boerema et al. 1987). P. calvescens has multiple synonyms, including $P$. chenopodii, $P$. halimiones, Pyrenophora calvescens, Chaetoplea calvescens, Leptosphaeria calvescens, and Phloeospora calvescens (de Gruyter et al. 2009). As fungal classification techniques have developed, the taxonomic status of Pleospora calvescens has changed greatly. Recent taxonomic revisions based on LSU, SSU, and ITS gene analyses have placed $P$. calvescens in the genus Neocamarosporium Crous \& Wingfield and identified it 
as $N$. calvescens (Ariyawansa et al. 2015; Wanasinghe et al. 2017). The classification of the Neocamarosporium (Crous \& Wingfield) genus was established in 2014 and comprises 15 species, including $N$. betae, $N$. chenopodii, $N$. obiones, and $N$. calvescens (Crous et al. 2014; Grum-Grzhimaylo et al. 2016; Papizadeh et al. 2018; Wanasinghe et al. 2017). N. calvescens (anamorph: A. caulina) has recently been reported in countries such as Germany and the Netherlands.

Currently, there are no systematic reports on quinoa black stem, as it is considered a new emerging disease of quinoa in China. This study described the symptoms of quinoa black stem, systematically characterized the fungus causing quinoa black stem, and determined the sensitivity of this pathogen to common fungicides and different temperatures, to provide a basis for the recognition and prevention of the disease.

\section{Materials and Methods}

Collection and isolation of samples. From flowering to the stage of maturity in 2017, typical black stems were collected from six quinoa plantations in Jingle County, Shanxi Province, China. All stem samples were initially examined using an Olympus BX53 microscope (Olympus, Japan) to further select test stem samples for pathogen isolation. For stem samples showing disease symptoms, the pathogens were directly picked from the lesions using a stereomicroscope and cultured on potato dextrose agar (PDA) (Solarbio, China) at $25^{\circ} \mathrm{C}$ for 5 to 7 days until colony formation (Sun et al. 2003). The colony was cultured on PDA at $25^{\circ} \mathrm{C}$ for 20 days until pycnidia formed. The resulting colonies were further purified by culturing single conidia according to the previously described procedure (Bai et al. 2015). Pycnidia were collected and ground, then diluted to a low concentration with sterilized water. The conidia dilutions were spread on PDA to generate discrete colonies. Pure fungi were obtained and stored in a refrigerator at $4^{\circ} \mathrm{C}$. Colony characteristics and microscopic observations of all isolates were examined to select representative isolates.

Morphological characterization of isolates. The representative isolates were cultured on PDA (Solarbio, China) at $25^{\circ} \mathrm{C}$ for 20 days, and the colony morphologies were observed. The representative isolates were inoculated on cellophane-coated PDA for culture at $25^{\circ} \mathrm{C}$. Pycnidia formation was observed using an Olympus BX53 microscope (Olympus, Japan).

Specimens with typical small black spots (pycnidia) were selected. These specimens were cut into small pieces $(0.5 \times 0.5 \mathrm{~cm})$. Tissue samples $(2 \mathrm{ml})$ were embedded in a tissue freezing medium (Leica, Germany). A Leica CM1950 cryostat was used to section the tissues to a thickness of 6 to $8 \mu \mathrm{m}$ at $-20^{\circ} \mathrm{C}$. Microscopic features such as pycnidia and conidia were observed and measured using an Olympus BX53 microscope.

In order to view the details of the pycnidia ultrastructures, electron microscopy was performed using a JSM-6390 (JEOL Ltd., Japan) scanning electron microscope. Specimens with small black spots were cut into small pieces of $\sim 1 \mathrm{~mm}^{3}$, immersed in a $2.0 \%$ glutaraldehyde solution ( $\mathrm{pH} 7.2$ ), and placed in a refrigerator at $4^{\circ} \mathrm{C}$ for $12 \mathrm{~h}$. After fixation, the samples were rinsed with $0.15 \%$ glutaraldehyde phosphate buffer and then dehydrated consecutively with 40, 70, 90 , and $100 \%$ ethanol for 15 min each time. After dehydration, the ethanol was replaced with amyl acetate, the samples were placed in a critical point drier, immersed in liquid carbon dioxide, and heated to above the critical temperature point of $31.4^{\circ} \mathrm{C}$ to dry by evaporation. After drying, the pycnidia were cut open, and a JEOL JEE-420 (JEOL Ltd., Japan) vacuum evaporator was used for gold sputtering. The ultrastructures of the pycnidia were then observed using a JSM6390 (JEOL Ltd., Japan) scanning electron microscope.

Effects of temperature on mycelium growth and conidia germination. Representative isolates were inoculated onto PDA and placed in an incubator with a temperature gradient of $0,5,10$, $15,20,25,30$, and $35^{\circ} \mathrm{C}$. Colony diameters were measured after 20 days when the pycnidia were mature.

Pycnidia were collected and ground from the representative isolates that were incubated on the PDA at $25^{\circ} \mathrm{C}$ for 20 days. A conidia suspension was prepared to a concentration of $1 \times 10^{5}$ conidia/ml with sterile water. This suspension $(100 \mu \mathrm{l})$ was inoculated onto a PDA-coated slide and placed in a desiccator with a relative humidity (RH) of $75 \%$ (saturated $\mathrm{NaCl}$ saline solution). The desiccator was used to provide an enclosed environment to maintain humidity. The desiccator was placed in an incubator and set to a temperature gradient of $0,5,10,15,20,25,30$, and $35^{\circ} \mathrm{C}$. After $12 \mathrm{~h}$, the conidia germination was examined by microscopy, and the germination rate was calculated. Each treatment was repeated three times, and 500 conidia were observed in each microscope slide prepared (Zang and Huang 2007).

A HOBO Pro V2 temperature/RH data logger (Onset, U.S.A.) was used to monitor the temperatures and $\mathrm{RH}$ in the incubator. The temperatures fluctuated within a range of $\pm 0.5^{\circ} \mathrm{C}$, and the $\mathrm{RH}$ fluctuated within a range of $\pm 2.0 \%$.

Molecular characterization of the isolates. Mycelia were cultured for 20 days, collected, and then ground in liquid nitrogen. DNA was extracted using an Ezup column fungi genomic DNA purification kit (Sangon Biotech [Shanghai] Co., Ltd., Shanghai, China). The LSU, SSU, and ITS sequences were amplified using three pairs of primers (Table 1). The PCR amplification procedures for the LSU, ITS, and SSU were as follows: predenaturation at $95^{\circ} \mathrm{C}$ for $5 \mathrm{~min}$, denaturation at $95^{\circ} \mathrm{C}$ for $90 \mathrm{~s}$, annealing for $90 \mathrm{~s}$, 35 cycles of extension at $72^{\circ} \mathrm{C}$ for $1 \mathrm{~min}$, and the final extension at $72^{\circ} \mathrm{C}$ for $10 \mathrm{~min}$. The annealing temperature for the LSU and ITS sequences was $55^{\circ} \mathrm{C}$, and the annealing temperature for the SSU was $48^{\circ} \mathrm{C}$ (Wanasinghe et al. 2017). The PCR products were determined using $1 \%$ agarose gel electrophoresis, and the products were recovered using a QIAquick gel extraction kit (Qiagen Inc., Valencia, CA). The PCR products were sent to Sangon Biotech (Shanghai) Co., Ltd. for sequencing, and the sequences were obtained and uploaded to GenBank (Table 2). Using Phoma drobnjacensis (CBS 269.92) as an outgroup, a phylogenetic tree was constructed based on the LSU, SSU, and ITS gene sequences by the neighborjoining method using PAUP* 4.0b10 software, with 1,000 repetitions (Swofford 2003).

Pathogenicity analysis. Pathogenicity on detached stems and leaves. Stem segments $(\sim 10 \mathrm{~cm}$ long and $\sim 2 \mathrm{~cm}$ in diameter) of $C$. album, $C$. bryoniifolium, and $C$. quinoa were collected from the quinoa fields at the flowering stage. The detached stems were sealed at both ends with Parafilm. Before inoculation, the stems were rinsed with sterile water several times and then air-dried. The conidia suspension $(200 \mu \mathrm{l})$ as described previously was drip dropped onto the unwounded stems of the quinoa. The control group was inoculated similarly with sterile water. Ten stems of quinoa, C. album, and $C$. bryoniifolium were inoculated for each treatment. The inoculated stems were placed in a climate chamber with a temperature gradient of $10,15,20,25,30$, and $35^{\circ} \mathrm{C}$ and $\mathrm{RH}=75 \pm 2.0 \%$. The symptoms were monitored and recorded over 6 to 10 days, until the experiment was complete. The length of the lesions was measured at 10 days postinoculation (dpi).

Detached leaves were collected at the flowering stage of C. album, C. bryoniifolium, and C. quinoa (white quinoa: Jingli No. 1, red quinoa: Jingli No. 3) from the quinoa fields. Before inoculation, detached leaves were rinsed with sterile water several times and then air-dried. For inoculation of the conidia, the $100 \mu l$ of suspension at a concentration of $1 \times 10^{5}$ conidia/ml was drip dropped onto the upper side of each leaf, and then the petiole was covered with sterilized cotton. Control leaves were inoculated in parallel using sterile water. After this, the inoculated leaves were incubated in climate chambers with a temperature gradient of $10,15,20,25,30$, and $35^{\circ} \mathrm{C}$, and $\mathrm{RH}=75 \pm 2.0 \%$, with $12 \mathrm{~h}$ of intermittent light. Each treatment was applied to three leaves and repeated five times. The symptoms were monitored and recorded over 3 to 8 days, until the experiment was complete. The lesion size of the leaf spot was measured 8 dpi.

Pathogenicity on intact stems and leaves. Healthy C. quinoa plants were inoculated on the stems at the flowering stage, which were cultivated in the greenhouse from seed (fluorescent cycle of $12 \mathrm{~h}$ light $/ 12 \mathrm{~h}$ dark at $22^{\circ} \mathrm{C}$ ). To investigate the pathogenicity of 
the fungal isolates outside, $C$. quinoa from the greenhouse were transplanted into pots and inoculated with $200 \mu \mathrm{l}$ of a condial spore solution prepared as previously described. Then the inoculated plants were placed outdoors in Taiyuan, Shanxi Province, China, from late October to November of 2019. The symptoms were recorded over 6 to 15 days. Pathogens were isolated again from the lesions after the development of disease and compared with the inoculated isolates (Lupien et al. 2017). Intact leaf inoculations

Table 1. Primers used to amplify LMHS-3 and LMHS-5 of Ascochyta caulina in this study

\begin{tabular}{lcc}
\hline Primer pair & Sequence 5' to 3' & Annealing temperature \\
\hline ITS1 & TCCGTAGGTGAACCTGCG & Amplified regions \\
ITS4 & TCCTCCGCTTATTGATATGC & ITS \\
LROR & ACC CGC TGA ACT TAA GC & $55^{\circ} \mathrm{C}$ \\
LR7 & TAC TAC CAC CAA GAT CT & \\
NS1 & GTAGTCATATGCTTGTCTC & $48^{\circ} \mathrm{C}$ \\
NS4 & CTTCCGTCAATTCCTTTAAG & SSU \\
\hline
\end{tabular}

Table 2. Isolates and GenBank accession numbers used for phylogenetic analysis

\begin{tabular}{|c|c|c|c|c|c|c|}
\hline \multirow[b]{2}{*}{ Species } & \multirow[b]{2}{*}{ Strain number } & \multirow[b]{2}{*}{ Previous name } & \multirow[b]{2}{*}{ Host plant } & \multicolumn{3}{|c|}{ GenBank accession number } \\
\hline & & & & LSU & SSU & ITS \\
\hline \multirow[t]{2}{*}{ Not yet determined } & LMHS-3 & - & Chenopodium quinoa & MN064796 & MN064798 & MN065158 \\
\hline & LMHS-5 & - & & MN064797 & MN064799 & MN065159 \\
\hline Neocamarosporium calvescens & CBS 246.79 & Pleospora calvescens & Atriplex hastata & MH872973 & EU754032 & KY940774 \\
\hline N. chenopodii & CBS 344.78 & P. chenopodii & Atriplex hastata & MH872910 & EU754033 & MH861148 \\
\hline$N$. obiones & CBS 432.77 & P. halimiones & Halimione portulacoides & MH872851 & JF740096 & MH861086 \\
\hline \multirow[t]{3}{*}{ N. betae } & CBS 109410 & Phoma betae & Beta vulgaris & MK249662 & MK249665 & KY940790 \\
\hline & CBS 523.66 & & & MH870520 & EU754080 & FJ426981 \\
\hline & ICMP 10945 & & & MK249661 & MK249664 & MK249658 \\
\hline \multirow[t]{2}{*}{ N. lamiacearum } & MFLUCC 17-560 & - & Lamiaceae spp. & MF434279 & MF434367 & MF434191 \\
\hline & MFLUCC 17-0750 & & - & MF434280 & MF434368 & MF434192 \\
\hline N. salicorniicola & MFLUCC 15-0957 & - & Salicornia spp. & MF434281 & MF434369 & MF434193 \\
\hline N. korfii & MFLUCC 17-0745 & - & - & MF434278 & MF434366 & MF434190 \\
\hline \multirow[t]{2}{*}{ N. salsolae } & MFLUCC 17-0827 & - & Salsola spp. & MF434283 & MF434371 & MF434195 \\
\hline & MFLUCC 17-0826 & & Salsola spp. & MF434282 & MF434370 & MF434194 \\
\hline Phoma drobnjacensis & CBS 269.92 & Subplenodomus drobnjacensis & Eustoma exaltatum & JF740285 & JF740100 & JF740211 \\
\hline
\end{tabular}

Table 3. Concentration of the seven fungicides used in this study

\begin{tabular}{lcc}
\hline Fungicide & Concentration on conidia germination $(\boldsymbol{\mu g} / \mathbf{m l})$ & Concentration on mycelia growth $(\boldsymbol{\mu} \mathbf{g} / \mathbf{m l})$ \\
\hline Carbendazim & $350,300,250,200,150$ & $5,4,3,2,1$ \\
Tebuconazole & $350,300,250,200,150$ & $0.1,0.05,0.025,0.01,0.0005$ \\
Prochloraz & $120,100,80,70,60$ & $8,4,2,1,0.5$ \\
Difenoconazole & $100,90,80,70,60$ & $0.1,0.05,0.025,0.01,0.0005$ \\
Thiophanate-methyl & $80,70,60,50,40$ & $6,3,1.5,1,0.5$ \\
Azoxystrobin & $20,10,5,2.5,1$ & $1,0.5,0.25,0.125,0.1$ \\
Mancozeb & $10,8,5,2.5,1$ & $1,0.5,0.25,0.125,0.1$ \\
\hline
\end{tabular}
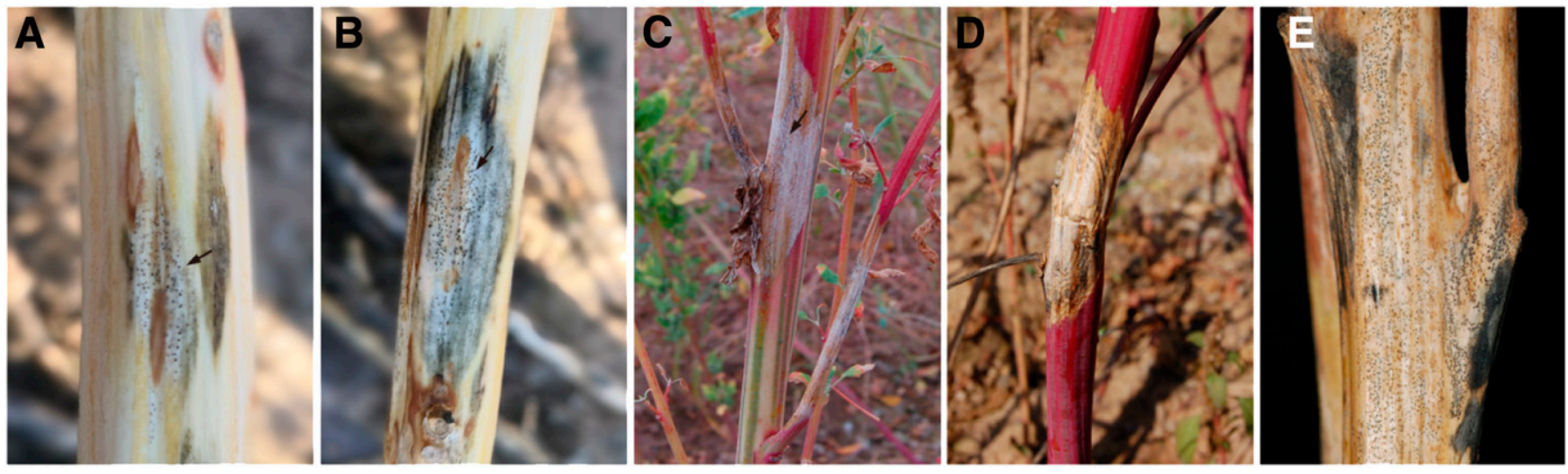

Fig. 1. Typical symptoms of quinoa black stem on Chenopodium quinoa in the field. A, New developed diamond shaped lesions on quinoa stem. Arrows indicate the pycnidia on the stems. B and C, Pycnidia on the infected stems of white quinoa (B) and red quinoa (C). D, Lodging symptoms of quinoa black stem. E, Pycnidia on a dead stem of quinoa. 
were performed at the flowering stage of $C$. album, C. bryoniifolium, and $C$. quinoa cultivated in the greenhouse. A conidia suspension $(100 \mu \mathrm{l})$, at a concentration of $1 \times 10^{5} \mathrm{conidia} / \mathrm{ml}$, was inoculated onto the upper side of each leaf. The control group was inoculated with sterile water. Three replicates were performed for the inoculation. The symptoms were monitored and recorded over 5 to 10 days until the experiment was complete. Pathogens were isolated again from the lesions after the development of the disease and compared with the inoculated isolates (Lupien et al 2017).
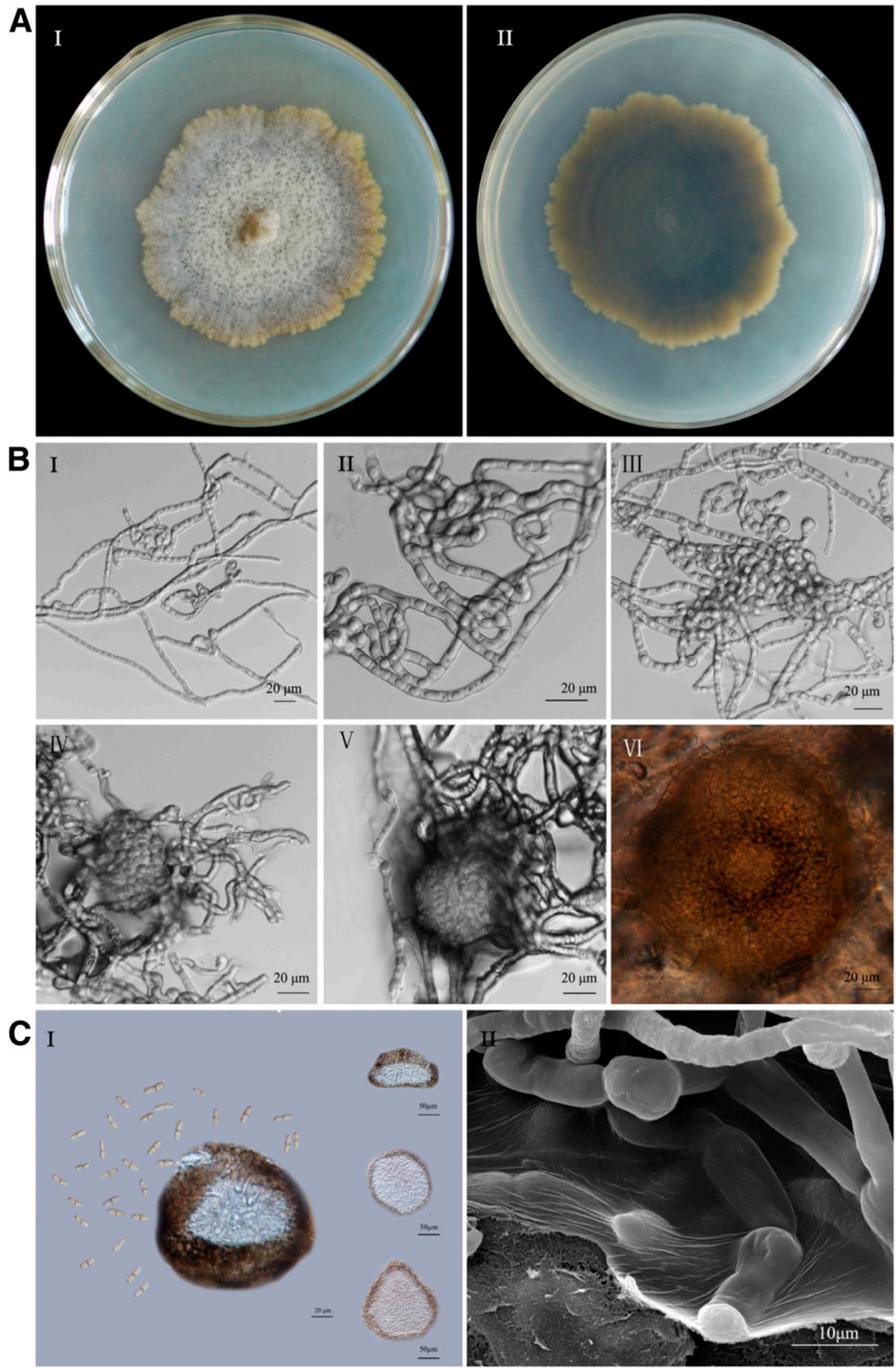

Fig. 2. Morphologies of the representative isolates of quinoa black stem. A, Views of the surface (I) and the bottom (II) of the colony from the PDA plate of the representative isolate B, Formation of pycnidia and the adjacent mycelia connection and fusion (I), further gathered around the center (II), and becoming pycnidial primordia (III); pycnidial primordia became subglobose (IV) and further expanded (V) until primordia matured (VI). C, Morphological characteristics of the pycnidia and conidia (I), and the ultrastructure of the pycnidia (II). 
Pathogenicity on roots. Before sowing, the seeds of the C. quinoa and $C$. album were rinsed with sterile water several times and then air-dried. Seeds were sown into pots with sterilized peat moss. Pots were placed in a climate chamber (fluorescent cycle of $12 \mathrm{~h} \mathrm{light} / 12 \mathrm{~h}$ dark, $\mathrm{RH}=45 \pm 2.0 \%$, at $22^{\circ} \mathrm{C}$ ). Plants were grown for 2 weeks and were approximately 10 to $12 \mathrm{~cm}$ tall when they were inoculated. For inoculation, each plant was drenchtreated with $100 \mathrm{ml}$ of the conidia suspension as described previously. The controls were inoculated with sterile water. To examine the underground symptoms, soil attached to the roots was gently washed, then photographed 2 weeks postinoculation.

Sensitivity of mycelial growth and conidia germination to seven fungicides. Azoxystrobin (97.50\%), difenoconazole (97\%), and tebuconazole (97\%) were each dissolved in methanol to prepare $1.0 \times 10^{4} \mu \mathrm{g} / \mathrm{ml}$ stock solutions. Mancozeb (85\%), thiophanate-methyl (95\%), and prochloraz (95\%) were each dissolved in acetone to prepare $1.0 \times 10^{4} \mu \mathrm{g} / \mathrm{ml}$ stock solutions. Carbendazim (96\%) was dissolved in $0.1 \mathrm{~mol} / \mathrm{liter}$ dilute hydrochloric

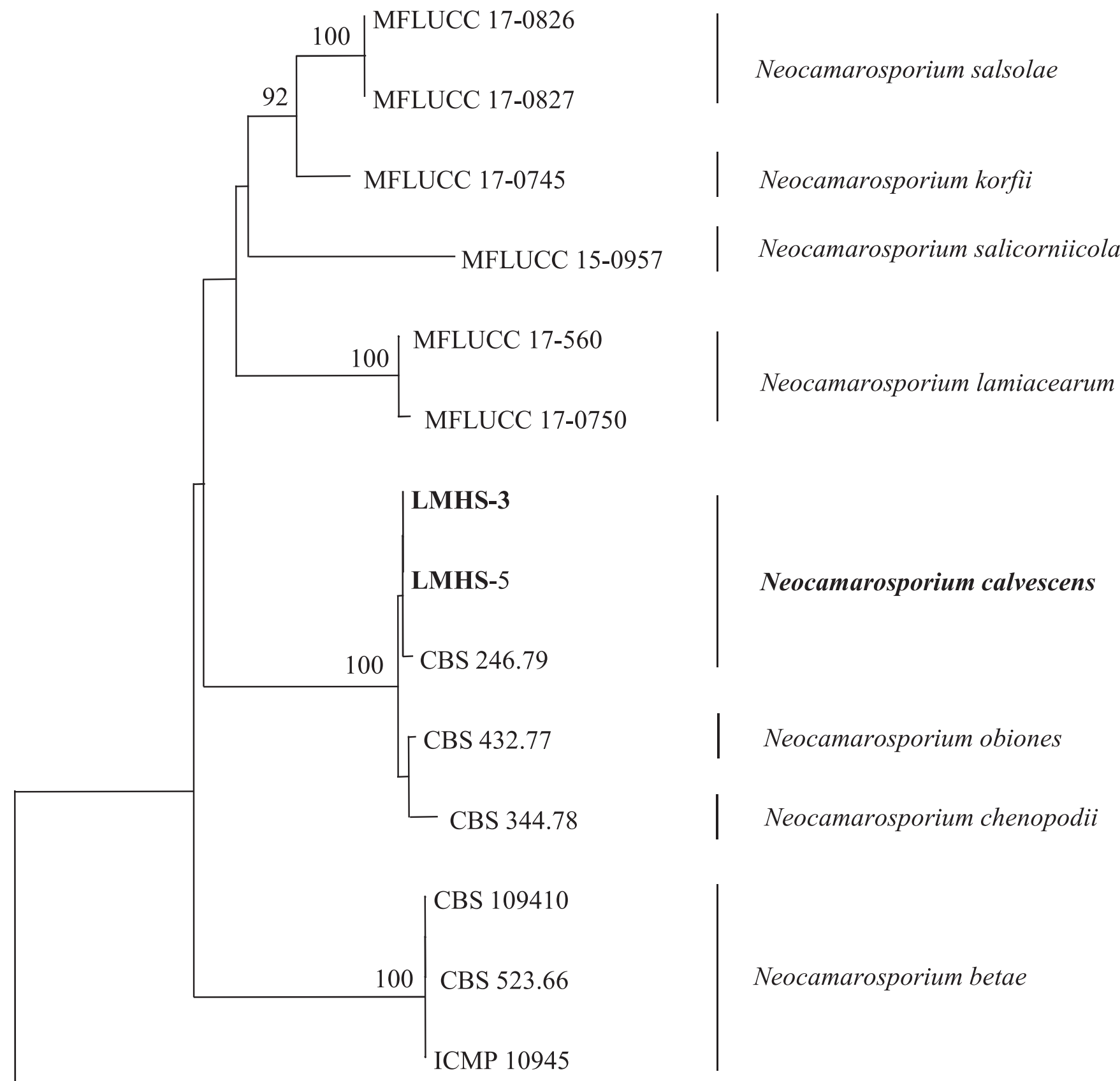

CBS 269.92 Phoma drobnjacensis

0.01

Fig. 3. Phylogenetic tree of Neocamarosporium calvescens (anamorph: Ascochyta caulina) isolates (LMHS-3 and LMHS-5) and its related isolates based on LSU, SSU, and ITS sequences using the neighbor-joining method. Phoma drobnjacensis was used as an outgroup. Bootstrap values (expressed as percentages of 1,000 replications) were shown at the major branching points. The scale bar represents 0.1 substitutions per nucleotide. 
acid to prepare a $1.0 \times 10^{4} \mu \mathrm{g} / \mathrm{ml}$ stock solution (Hou et al. 2014; Huang et al. 2016; Xu et al. 2016).

The seven fungicidal stock solutions were diluted into serial dilutions using sterile water and added to PDA at $\sim 50^{\circ} \mathrm{C}$ to prepare the plates and slides (Table 3 ). Preliminary testing showed that the volume fractions of the methanol, acetone, or hydrochloric acid were less than $0.25 \%$; this did not affect the mycelial growth or spore germination of representative isolates. Therefore, the same volumes of acetone, methanol, and hydrochloric acid were added to PDA as a blank control. The serial dilutions of azoxystrobin were supplemented with $100 \mathrm{mg} / \mathrm{liter}$ of the alternative oxidase pathway inhibitor salicylhydroxamic acid (Huang et al. 2016).

Spore germination was used to determine the sensitivity of the spores to the fungicides. PDA containing different serial dilutions of the seven fungicides was prepared (Table 3), $200 \mu$ l of each of the fungicide-containing PDAs were applied to the slides, and $100 \mu \mathrm{l}$ of conidia suspension $\left(1 \times 10^{5} \mathrm{cfu} / \mathrm{ml}\right)$ was inoculated onto the slides after agar solidification, and they were incubated for $12 \mathrm{~h}$ at $25^{\circ} \mathrm{C}$ in the dark. Conidia germination was counted to determine the spore germination inhibition rate (Huang et al. 2016).
The mycelial growth rate method was used to determine the sensitivity of the mycelia to the fungicides. A disk of the representative isolates (diameter: $0.5 \mathrm{~cm}$ ) was inoculated into the center of the fungicide-containing PDA, and a blank PDA medium was used as the control. After culturing for 5 days at $25^{\circ} \mathrm{C}$, the colony diameters were measured using the cross lines method in two directions, and each treatment was replicated three times to calculate the inhibition rate (Hou et al. 2014; Xu et al. 2016).

Inhibition rate $(\%)=\frac{(\text { Diameter of control fungal colony }-0.5)-}{\text { Diameter of treated fungal colony }-0.5)}-100 \%$

The logarithm of the concentration of each treatment fungicide represented the independent variable $(\mathrm{X})$, and the probability of the corresponding spore germination or mycelial growth inhibition rate represented the dependent variable (Y). The regression method was used to fit the virulence regression curve to yield the regression equation. In addition, the $\mathrm{EC}_{50}$ value was determined according to the regression equation (Hou et al. 2014; Xu et al. 2016).

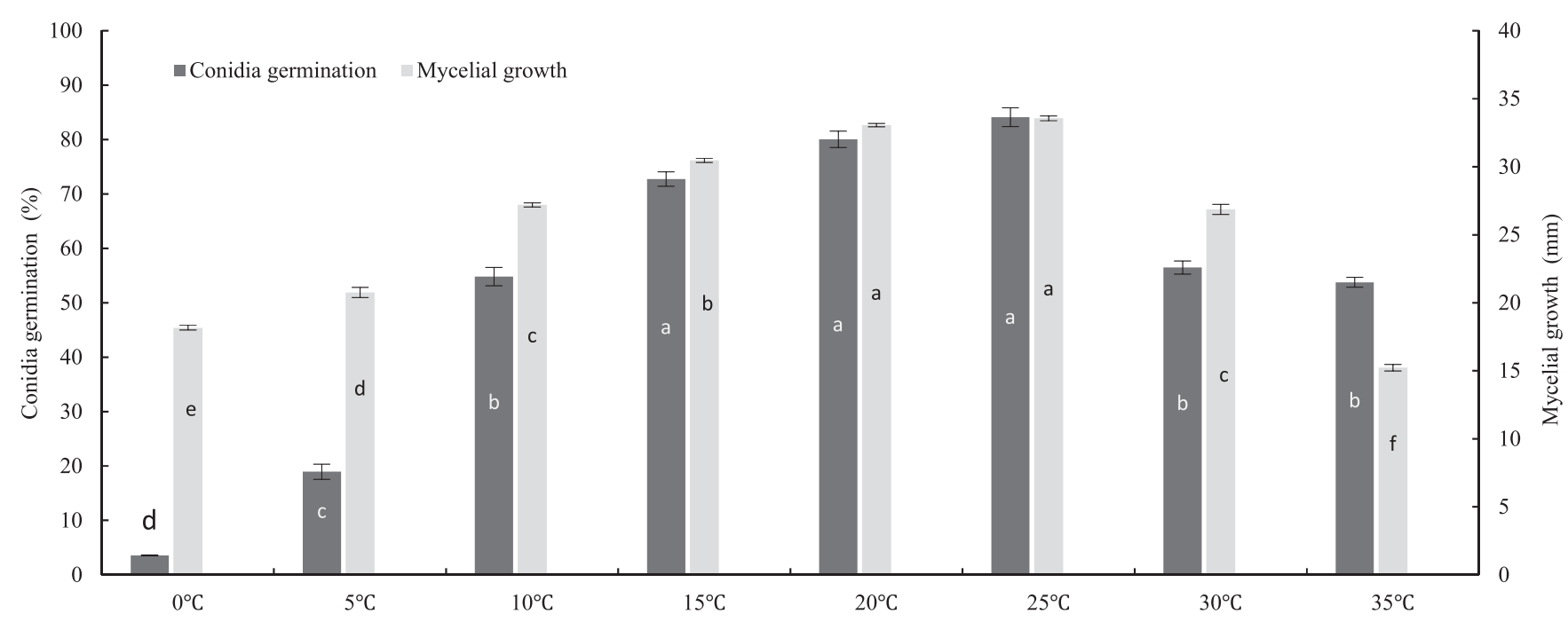

Fig. 4. Effect of temperature on in vitro mycelial growth and conidia germination of Ascochyta caulina. Data were analyzed with SPSS statistics 19.0 by one-way ANOVA, and means were compared using Tukey's test at a significance level of $P=0.05$. Different letters indicate significant differences $(P=0.05)$. Bars and error bars represent means \pm SDs $(n=3)$.
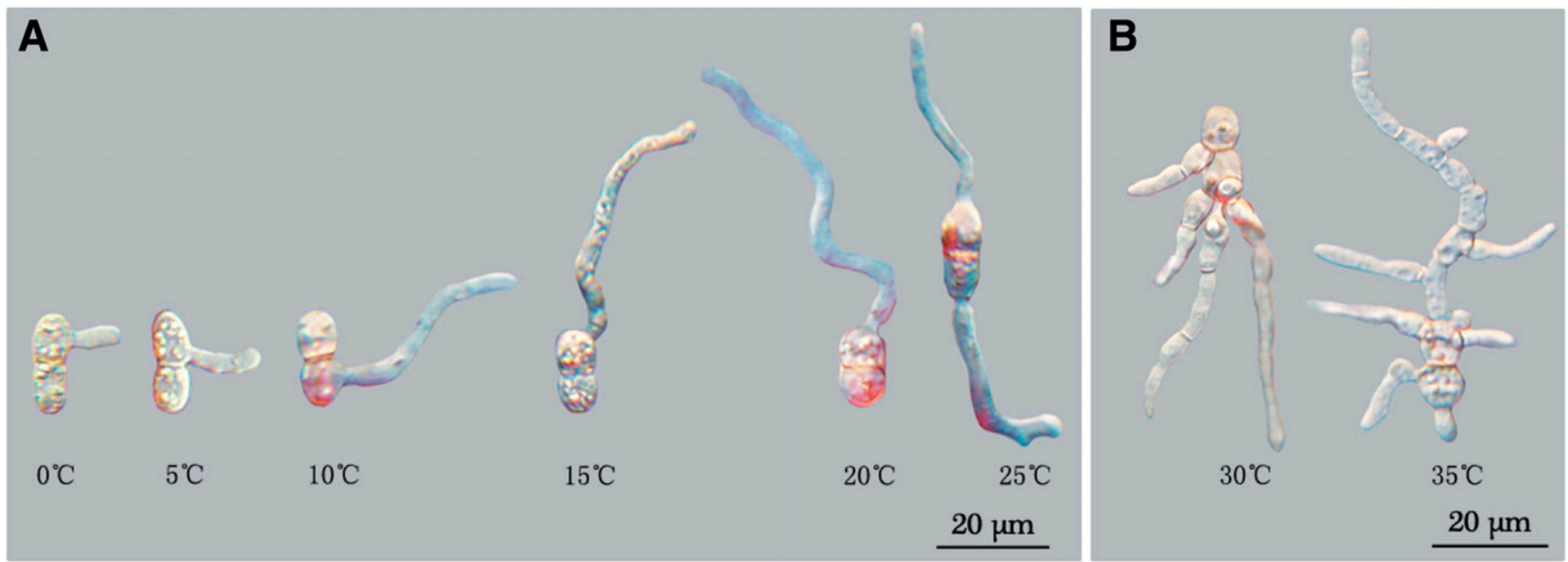

Fig. 5. Germination of the conidia of Ascochyta caulina at different temperatures. A, Normal germination of the conidia at $0,5,10,15,20$, and $25^{\circ} \mathrm{C}$, respectively. B, Malformed germination of the conidia at 30 and $35^{\circ} \mathrm{C}$. 
Data statistics and analysis. One-way analysis of variance (ANOVA) was conducted using SPSS (version 19.0; IBM, Armonk, NY) and means were compared using Tukey's test at a significance level of $P=0.05$. Homogeneity of the variance was tested before analysis.

\section{Results}

Field symptoms and loss survey. This disease primarily affected the stems of the quinoa plants. The lesions were diamond shaped and first appeared in the middle and lower parts of the stems, and gradually expanded upward. In the early stages of this disease, the lesions were seen to be pale or tan, and the margins between the lesions and healthy tissue were clear. There were slight depressions, as the plants were prone to drying and consequent shrinkage, and there were small round protrusions on the surface of the lesions (Fig. 1A). In the later stages, the lesions were black and accompanied by a large number of small black spots, the pycnidia of the pathogen, usually below the epidermis of the host. In severe cases, the lesions wrapped around the stem, causing lodging, foliar chlorosis, and leaf abscission. The diameters of lesions ranged from 5.9 to $9.6 \mathrm{~cm}($ mean $=7.9 \mathrm{~cm})($ Fig. 1B-D). Quinoa black stem was found on both live and dead quinoa stems (Fig. 1B-E).

Morphology characteristics of the Ascochyta isolates. Thirty stem samples were selected for pathogen isolation, and a total of 13 isolates of pure fungi were obtained and stored. The 13 isolates were identical and showed typical colony characteristics and microscopic observations of A. caulina (teleomorph: $N$. calvescens). Hence, the representative isolates LMHS-3 and LMHS-5 were selected for the investigation from two different quinoa plantations in Jingle County, Shanxi Province. The colonies of the LMHS-3 and LMHS-5 isolates were semi-buried in PDA. The surface of the colony was velvety, centrally protruding, grayish white but yellowish brown at the margins, and feathery. The bottom of the colony was dark brown at the center and yellowish brown at the edges. After culturing on PDA for 7 days, the colony surface had fine particles that enlarged continuously and became black; there were maturing pycnidia for 20 days that were densely distributed in the center of the colony (Fig. 2A).

The hyphae were light brown with shrunken septa, with a width of 4.40 to $6.96 \mu \mathrm{m}($ mean $=5.56 \mu \mathrm{m})$. Adjacent hyphae were fused and entangled through frequent separation and branching of the multiple hyphae and were expanded around the center to form a primordial pycnidium. After the primordial pycnidium was formed, the hyphae continued to branch, enlarge, and produce brown pigments. In the center of the mycelial aggregation, part of the hyphae differentiated into thick-walled cells, the hyphae were closely entangled, and the spores gradually developed (Fig. 2B).
The pycnidia were observed to be hard textured, grayish-white or light brown in color, nearly spherical or pear-shaped, with a single chamber. The outer surfaces of the pycnidia had polygonal lattice patterns. The spore wall thickness ranged from 5.76 to $7.02 \mu \mathrm{m}$ $($ mean $=6.52 \mu \mathrm{m})$. Pycnidia were 124.53 to $230.34 \mu \mathrm{m} \times 87.05$ to $227.27 \mu \mathrm{m}$ in size $($ mean $=162.39 \times 138.96 \mu \mathrm{m})$. The mycelia on the inner wall of the mature pycnidia were dense and smooth. Conidiogenous cells differentiated from the inner wall cells, were usually distributed in the cavity of the inner wall of the pycnidia, and were nearly conical in shape. The conidia grew individually and were elliptical or fusiform in shape, light brown in color, and usually had a septum, which was slightly constricted, erect or curved, oblong at the top, flat at the base, and 15.40 to $24.47 \mu \mathrm{m} \times 4.43$ to $7.70 \mu \mathrm{m}$ in size $($ mean $=16.69 \times 5.91 \mu \mathrm{m})($ Fig. $2 \mathrm{C})$.

Molecular characterization and phylogenetic analysis of the Ascochyta isolates. The LSU, SSU, and ITS gene sequences of isolates LMHS-3 and LMHS-5 were amplified, and the sequences obtained were submitted to GenBank (Table 2). A phylogenetic tree was constructed using Phoma drobnjacensis (CBS 269.92) as the outgroup. The results showed that the isolates LMHS-3 and LMHS-5 clustered in the same large branch with the three species in the Neocamarosporium Crous \& Wingfield genus ( $N$. calvescens, $N$. obiones, $N$. chenopodii) with a $100 \%$ bootstrap support rate. LMHS-3 and LMHS-5 clustered in a small branch with CBS 246.79 with a $100 \%$ bootstrap support rate, indicating that it had the closest relationship with $N$. calvescens (Fig. 3). Collectively, the morphology, molecular characterization, and pathology confirmed $N$. calvescens (anamorph: A. caulina) as the causal agent of quinoa black stem.

Effect of temperature on mycelial growth, conidia germination, and the pathogenicity of the Ascochyta isolates. The conidia of A. caulina (teleomorph: $N$. calvescens) germinated in a wide range of temperatures, from 0 to $35^{\circ} \mathrm{C}$, and temperature had a significant effect on conidia germination (Fig. 4). The optimum temperature range for the germination of A. caulina conidia was 15 to $25^{\circ} \mathrm{C}$; the germination rate ranged from 73 to $84 \%$. Differences between the temperature treatments in this range were not significant. At temperatures below $15^{\circ} \mathrm{C}$ or above $25^{\circ} \mathrm{C}$, the germination rates of the conidia were significantly decreased. At 10,30 , and $35^{\circ} \mathrm{C}$, the germination rates were 55,56 , and $54 \%$, respectively; the differences of which were not significant. At temperatures $<5^{\circ} \mathrm{C}$, the germination rate was reduced to less than 19\% (Fig. 4).

Temperature had a significant effect on the mycelial growth of $A$. caulina (Fig. 4). The mycelia of A. caulina were found to grow best at 20 to $25^{\circ} \mathrm{C}$, reaching colony diameters of 33.07 to $33.57 \mathrm{~mm}$;

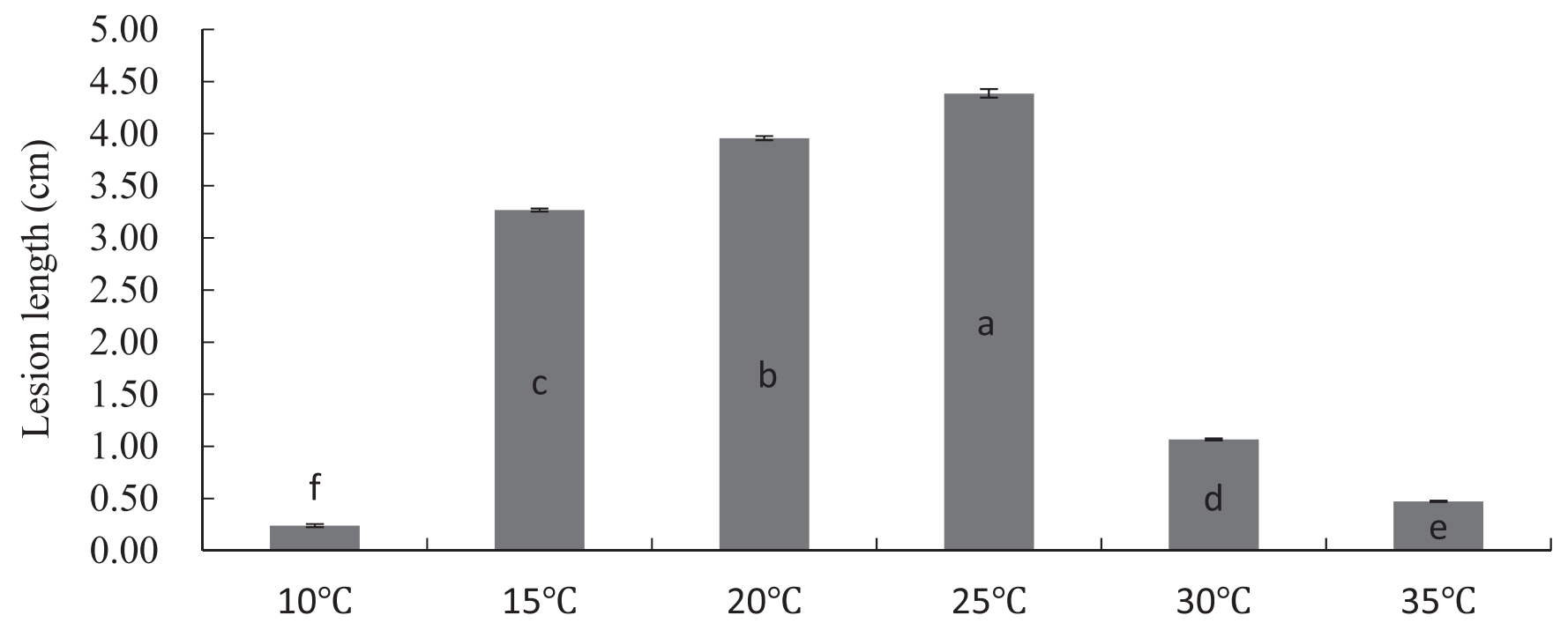

Fig. 6. Lesion length on quinoa stems that were inoculated with the Ascochyta isolate and incubated at different temperatures. Data were analyzed with SPSS statistics 19.0 by oneway ANOVA, and means were compared using Tukey's test at a significance level of $P=0.05$. Different letters indicate significant differences $(P=0.05)$. Bars and error bars represent means $\pm \operatorname{SDs}(n=3)$. 
differences between temperature treatments in this range were not significant. At temperatures below $20^{\circ} \mathrm{C}$ or above $25^{\circ} \mathrm{C}$, the mycelial growth was significantly decreased. At temperatures below $5^{\circ} \mathrm{C}$ or above $35^{\circ} \mathrm{C}$, the colony mean diameters were $<20.00 \mathrm{~mm}$ (Fig. 4).

The conidia of A. caulina were able to germinate normally at temperatures in the range of 0 to $25^{\circ} \mathrm{C}$. The germ tubes were able to germinate from the two ends or the sides of the conidia, from one or both ends, and rarely from the branches (Fig. 5A). At temperatures $>30^{\circ} \mathrm{C}$, the germination of $A$. caulina conidia was malformed, and presented an altered mode of conidial germination whereby the germ tubes emerged from three or more sites on the conidia. In addition, the base or tip of the germ tubes were swollen or showed more branching (Fig. 5B).

Temperature had a significant effect on the pathogenicity of $A$. caulina. A. caulina was pathogenic between 15 and $25^{\circ} \mathrm{C}$, and the length of the lesions ranged from 3.27 to $4.39 \mathrm{~cm}$. The optimal pathogenic temperature of $A$. caulina was $25^{\circ} \mathrm{C}$, and the length of the lesions was $4.39 \mathrm{~cm}$, which was significantly higher than other treatments. When the temperature was below $10^{\circ} \mathrm{C}$ or above $35^{\circ} \mathrm{C}$,
A

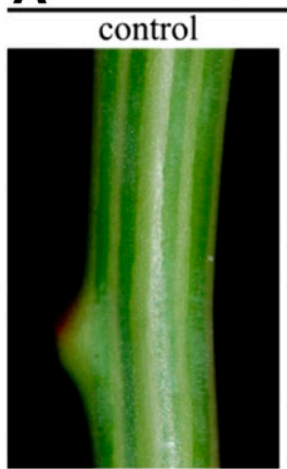

B

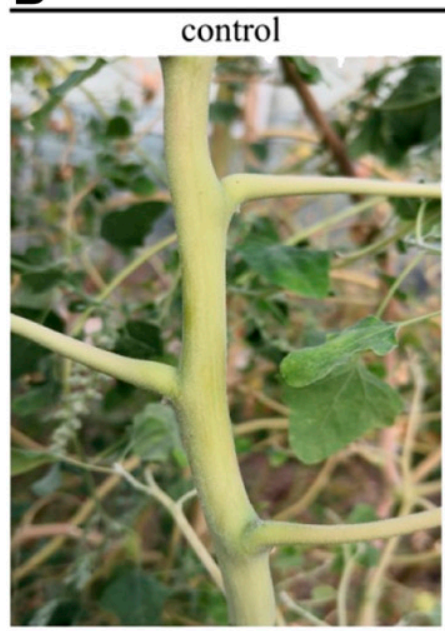

D
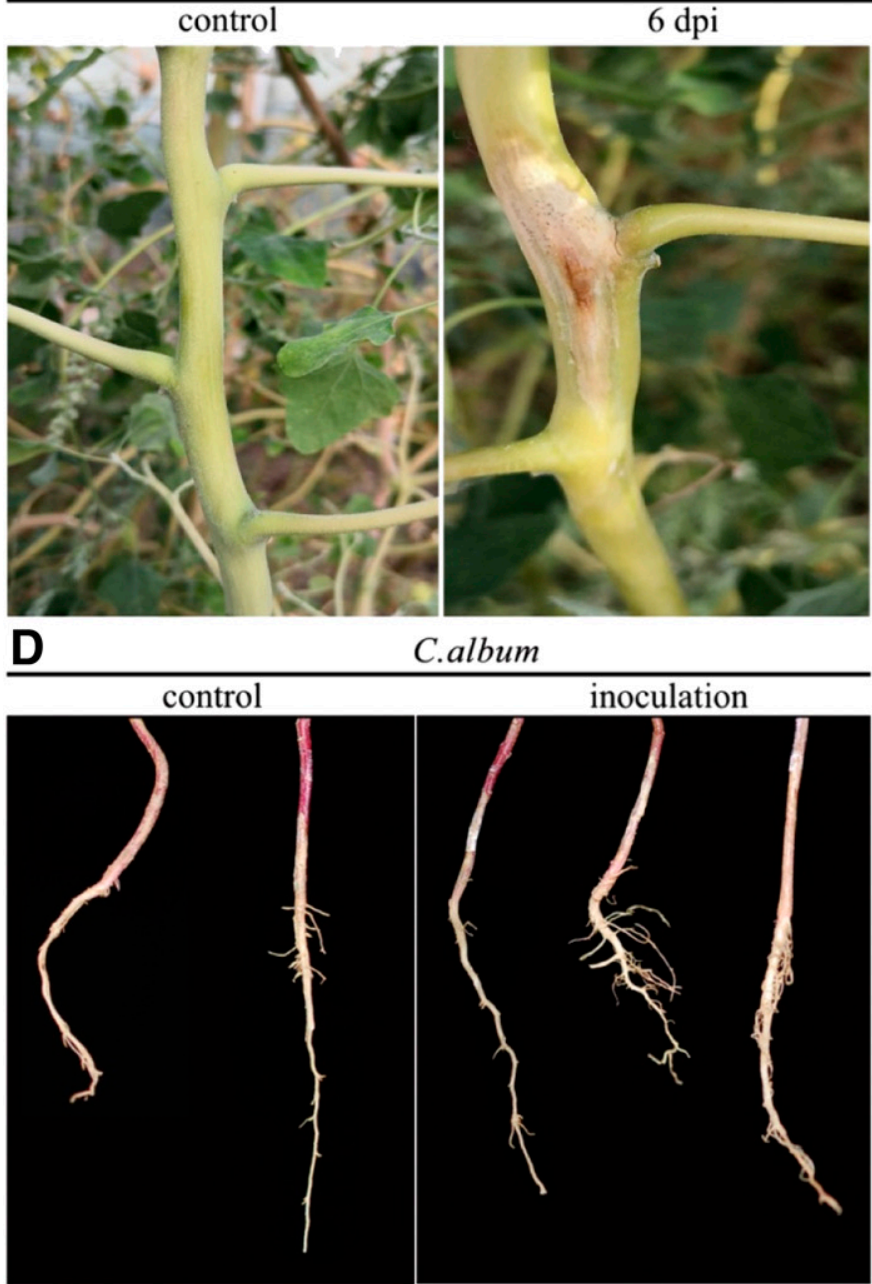

C. bryoniifolium
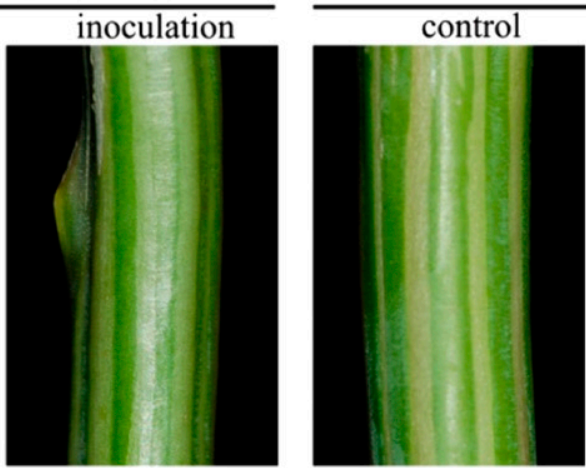

C. quinoa
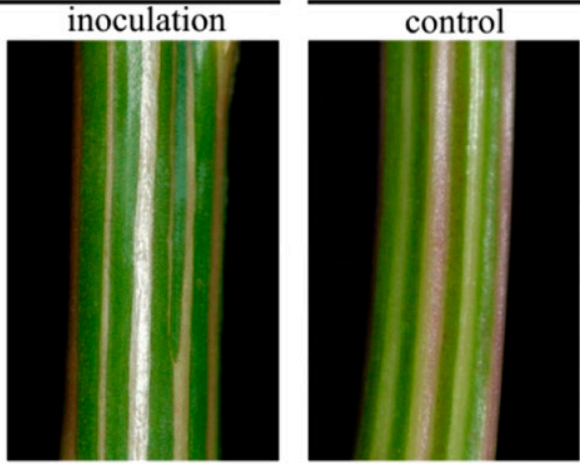

C

$15 \mathrm{dpi}$

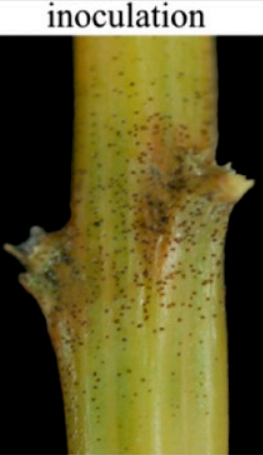

C. quinoa
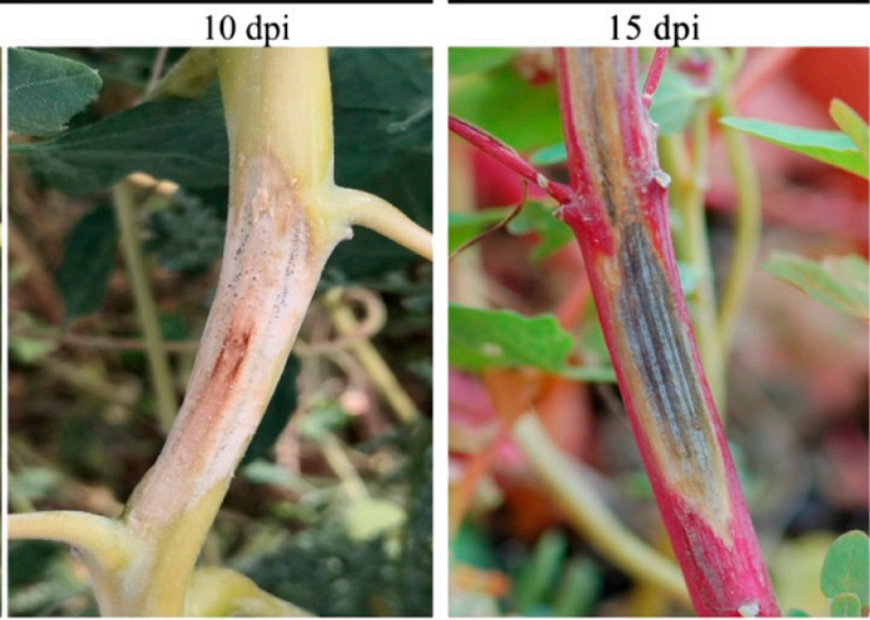

C.quinoa

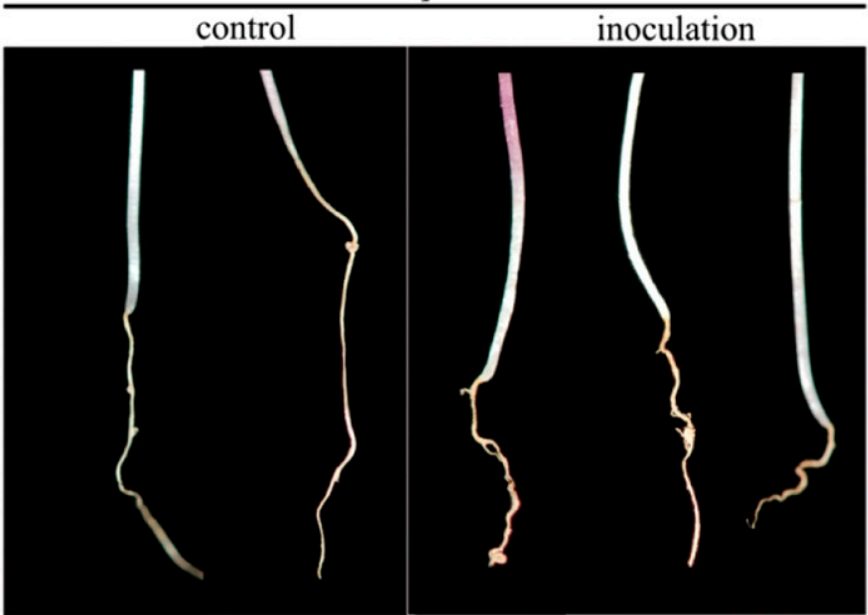

Fig. 7. Symptoms on Chenopodium album, C. bryonifolium, and C. quinoa stems induced by inoculation of representative isolate of Ascochyta caulina. A, Pathogenicity of $A$. caulina on stems of $C$. album, $C$. bryoniifolium, and $C$. quinoa under climate chamber conditions. B, Pathogenicity of $A$. caulina on stems of $C$. quinoa at different days postinoculation (dpi) under greenhouse conditions. C, Symptoms induced on quinoa stem by inoculation of $A$. caulina under outdoor conditions. $\mathrm{D}$, Pathogenicity of $A$. caulina on roots of $C$. album and $C$. quinoa under greenhouse condition, respectively. 
the length of the lesions was significantly reduced to less than $0.50 \mathrm{~cm}$ (Fig. 6).

Pathogenicity tests of the Ascochyta isolates. Pathogenicity tests on the detached stems of C. quinoa showed typical symptoms $10 \mathrm{dpi}$, whereas no symptoms developed on those treated with sterile water (Fig. 7A). At 10 dpi, the inoculation sites of the detached stems of $C$. quinoa were densely covered with small pycnidia that were bulging and black in color (Fig. 7A). The two isolates did not cause any disease symptoms on the detached stems of C. album and C. bryoniifolium (Fig. 7A). The control plant stems of $C$. album and $C$. bryoniifolium remained healthy (Fig. 7A).

When the intact stems of $C$. quinoa were inoculated, typical symptoms were observed by 6 dpi. At 6 dpi, obvious lesions were found at the inoculation sites, and the margins between lesions and healthy tissue were obvious, with a pale brown halo, a brown center, necrosis, and the accompanying small pycnidia (Fig. 7B). The lesions further developed and enlarged $10 \mathrm{dpi}$ (Fig. 7B), similar to the symptoms observed in the field (Fig. 1B and C). There were no symptoms on the control (Fig. 7B). To fulfill Koch's postulates, the pathogenicity analysis was further inoculated on $C$. quinoa in outdoor conditions. At 15 dpi, typical symptoms appeared on the stems of $C$. quinoa in outdoor conditions (Fig. 7C), which were identical to the original ones that had been observed (Fig. 1C and D). The two isolates did not cause any disease symptoms on the roots of $C$. quinoa and C. album (Fig. 7D). The roots of the C. quinoa and C. album control plants remained healthy (Fig. 7D).

\section{A C. album C. bryoniifolium}

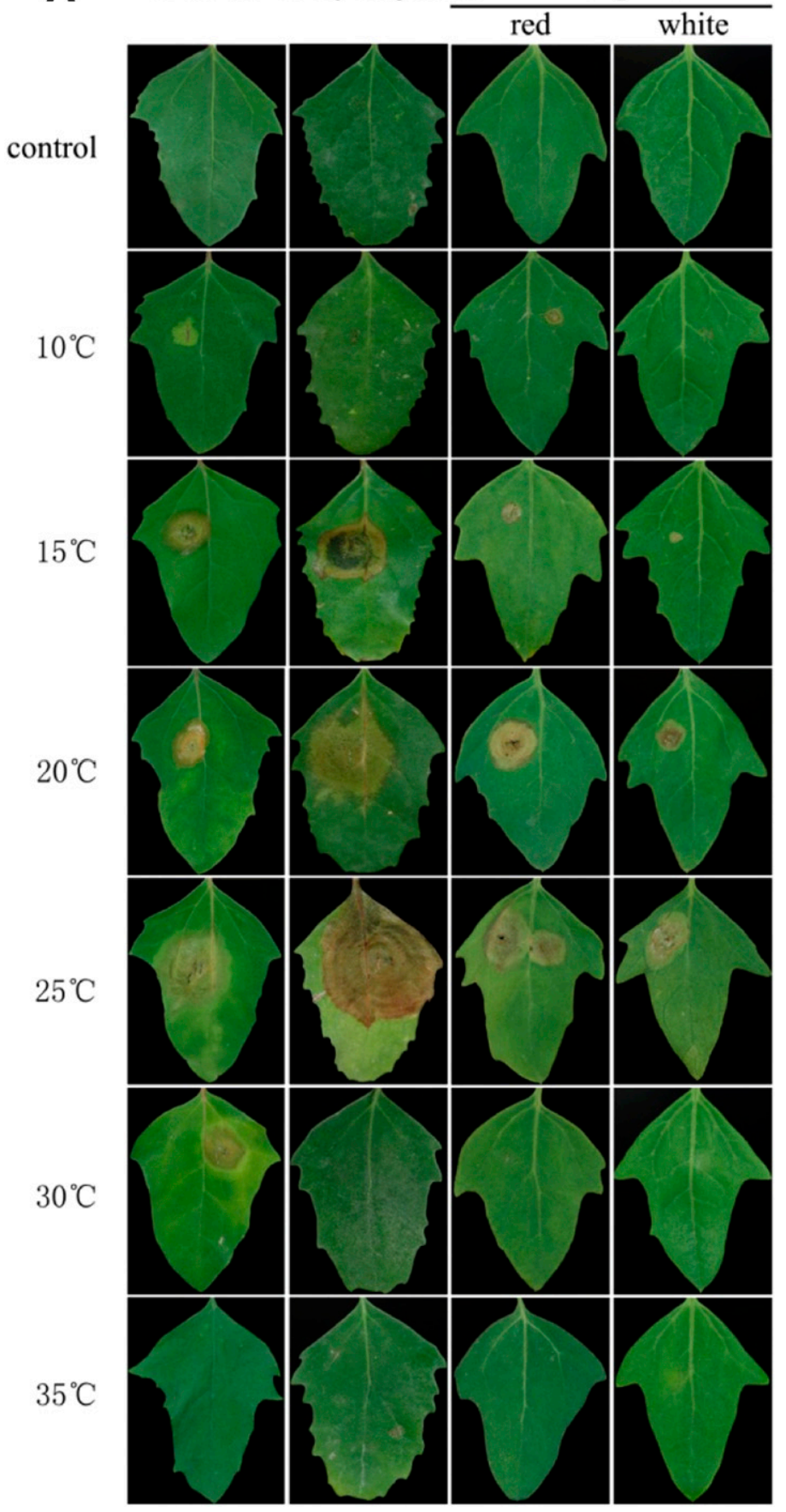

B

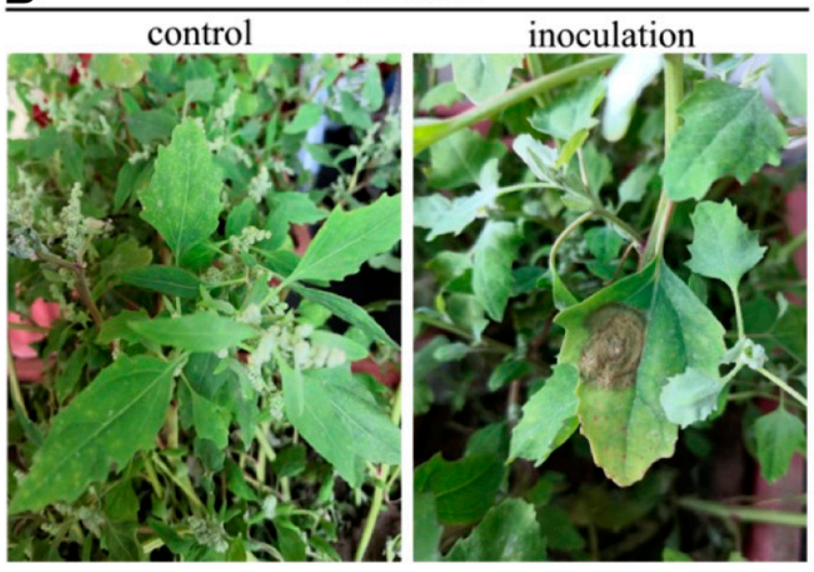

C

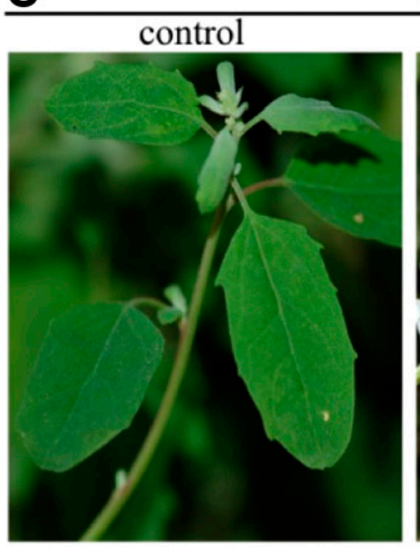

C. bryoniifolium

\section{D}

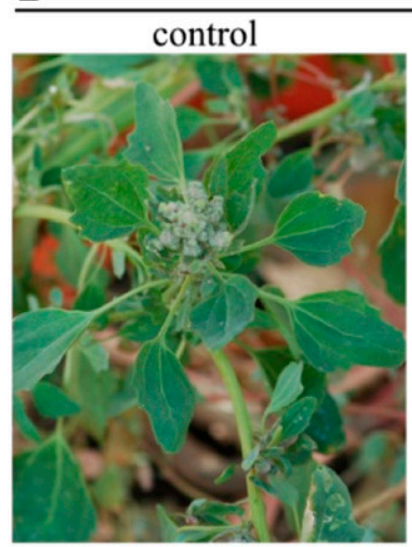

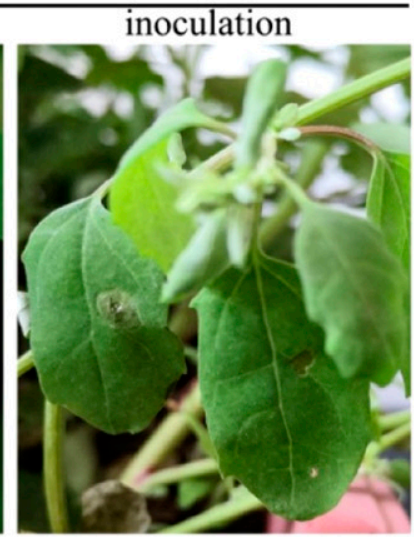

C. quinoa

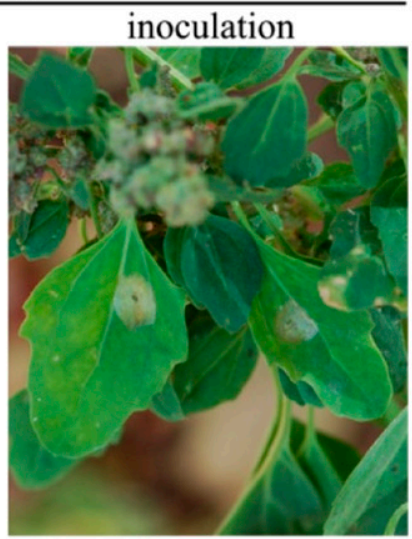

Fig. 8. Pathogenicity of Ascochyta caulina on Chenopodium album, C. bryoniffolium, and C. quinoa. A, Pathogenicity of $A$. caulina on detached leaves of $C$. album, C. bryoniifolium, and C. quinoa at $10,15,20,25,30$, and $35^{\circ} \mathrm{C}$, respectively. B, C, and D, Symptoms induced by inoculation of $A$. caulina on C. album, C. bryoniifolium, and C. quinoa under greenhouse conditions. 
The optimum temperature for disease onset in the detached leaves of $C$. album ranged from 20 to $30^{\circ} \mathrm{C}$. At $3 \mathrm{dpi}$, the lesions could be seen at the inoculation sites and the margins between lesions and healthy tissue were clear. At 6 dpi, the lesions had pale brown halos while their central parts were grayish white. The lesion sizes ranged from 0.62 to $2.53 \mathrm{~cm}$ at $8 \mathrm{dpi}$, when the small pycnidia were densely distributed at the inoculation sites in the $25^{\circ} \mathrm{C}$ treatment group. The optimum temperature for disease onset of the detached leaves of $C$. bryoniifolium ranged from 15 to $25^{\circ} \mathrm{C}$. The lesions could be observed at the inoculation sites after 4 and 7 days as brown to light brown with small pycnidia attached. At $8 \mathrm{dpi}$, lesion sizes ranged from 2.32 to $3.46 \mathrm{~cm}$, and the small pycnidia were most abundant at the sites inoculated at $25^{\circ} \mathrm{C}$. The optimum temperature for disease onset on the detached leaves of $C$. quinoa ranged from 10 to $25^{\circ} \mathrm{C}$. At 4 dpi, lesions were visible at the inoculation sites and at 8 dpi the lesions were grayish white. Lesion sizes ranged from 0.37 to $2.16 \mathrm{~cm}$ on the red quinoa and from 0.24 to $1.87 \mathrm{~cm}$ on the white quinoa. At 15 to $25^{\circ} \mathrm{C}$, the pycnidia were present at inoculation sites of the red quinoa leaves. The amount of small pycnidia on the red quinoa leaves was obviously more than that on the white quinoa leaves. During the experimental period, no disease occurred in the control groups or the $35^{\circ} \mathrm{C}$ groups of C. album, C. bryoniifolium, or C. quinoa leaves (Fig. 8A).

Pathogenicity analysis of A. caulina was further tested on intact leaves of $C$. album, $C$. bryoniifolium, and $C$. quinoa in the greenhouse. Typical brown spots clearly appeared on the intact leaves of C. album, $C$. bryoniifolium, and $C$. quinoa after 6,7 , and 8 dpi, respectively (Fig. 8B-D). Typical brown spots on the intact leaves

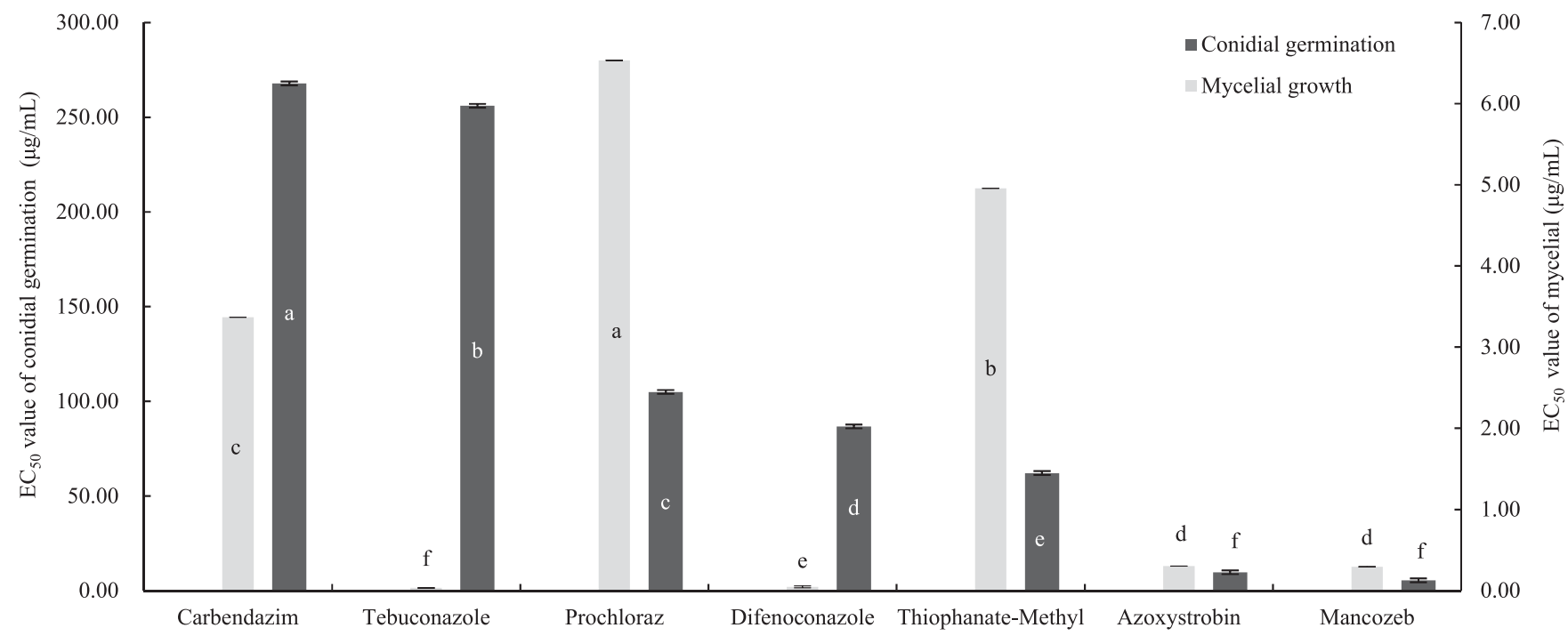

Fig. 9. Inhibition activities of seven fungicides on mycelial growth and conidial germination of Ascochyta caulina. Data were analyzed with SPSS statistics 19.0 by one-way ANOVA, and means were compared using Tukey's test at a significance level of $P=0.05$. Different letters indicate significant differences $(P=0.05)$. Bars and error bars represent means \pm SDs $(n=3)$.
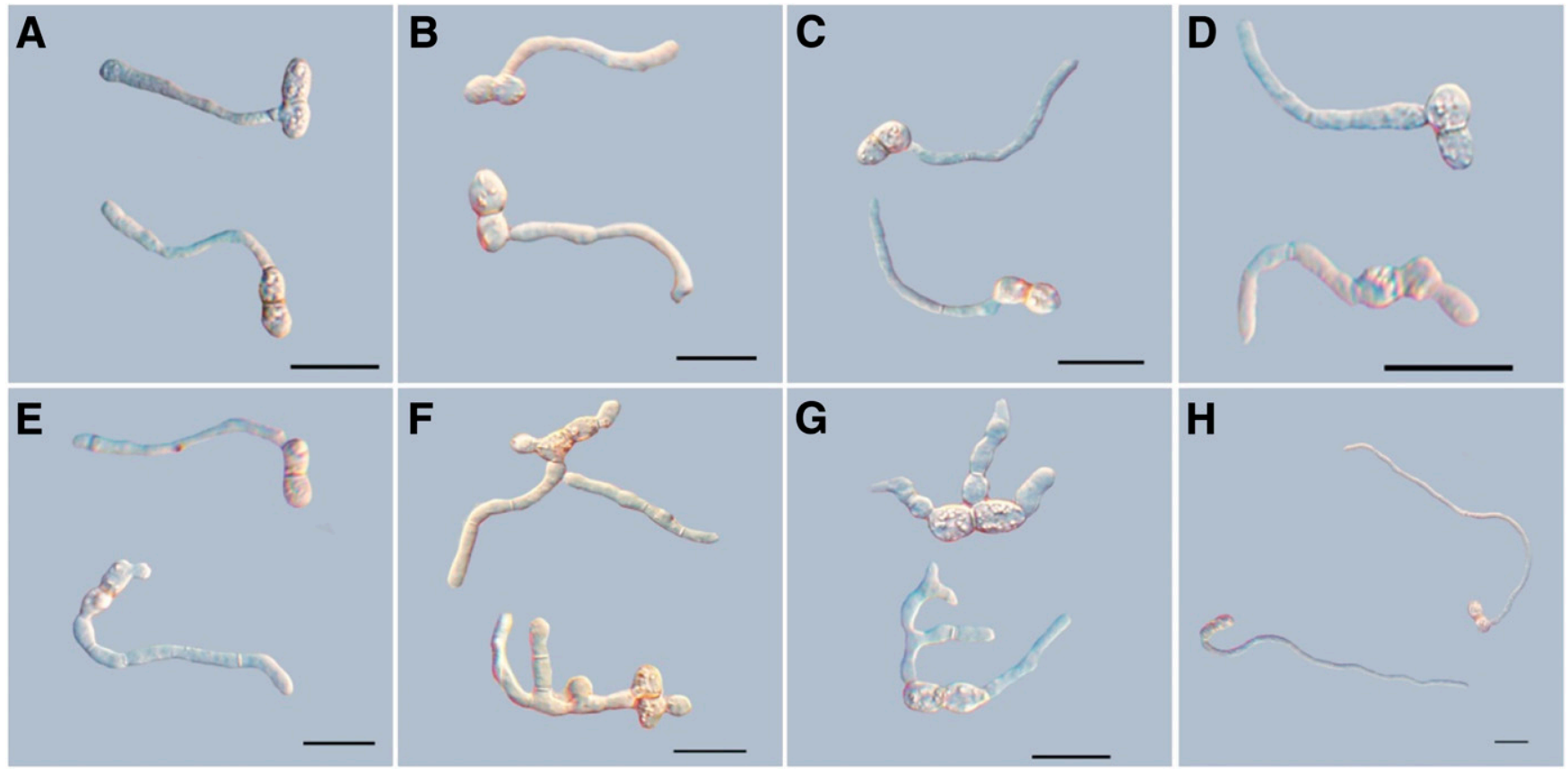

Fig. 10. Morphology of conidia and germ tubes of Ascochyta caulina treated with different concentrations of seven fungicides for $12 \mathrm{~h}(\mathbf{A}-\mathbf{G})$ and a control treatment $(\mathbf{H})$. A, Carbendazim $(1 \mu \mathrm{g} / \mathrm{ml})$. B, Tebuconazole $(0.0005 \mu \mathrm{g} / \mathrm{ml})$. C, Prochloraz $(0.5 \mu \mathrm{g} / \mathrm{ml})$. D, Difenoconazole $(0.0005 \mu \mathrm{g} / \mathrm{ml})$. E, Thiophanate-methyl $(0.5 \mu \mathrm{g} / \mathrm{ml})$. F, Azoxystrobin $(0.1 \mu \mathrm{g} / \mathrm{ml})$. G, Mancozeb $(0.1 \mu \mathrm{g} / \mathrm{ml})$. 
further developed, which were identical to the detached leaves of $C$. album, C. bryoniifolium and C. quinoa (Fig. 8).

The reobtained isolates from the inoculation-induced diseased stems and leaves showed that colony morphology and microscopic observations were identical to the ones for inoculation. Pathogenicity testing fulfilled Koch's postulates and indicated that the isolates LMHS-3 and LMHS-5 were pathogens.

Effects of seven fungicides on mycelia growth and conidia germination of the Ascochyta isolates. In order of decreasing toxicity on the conidial germination of A. caulina, the seven tested fungicides were mancozeb, azoxystrobin, thiophanate-methyl, difenoconazole, prochloraz, tebuconazole, and carbendazim; the $\mathrm{EC}_{50}$ values were 5.426, 9.716, 62.114, 86.740, 104.946, 256.039, and $267.834 \mu \mathrm{g} / \mathrm{ml}$, respectively. The fungicides that most strongly inhibited the conidial germination of A. caulina were mancozeb and azoxystrobin; the differences between the two were not significant, but the differences compared with the other five fungicides were significant (Fig. 9).

In order of decreasing toxicity on the mycelial growth of $A$. caulina, the seven tested fungicides were tebuconazole, difenoconazole, azoxystrobin, mancozeb, carbendazim, thiophanate-methyl, and prochloraz; the $\mathrm{EC}_{50}$ values were $0.034,0.047,0.295,0.303,3.369$, 4.957, and $6.534 \mu \mathrm{g} / \mathrm{ml}$, respectively. The fungicides that most strongly inhibited the mycelial growth of A. caulina were tebuconazole and difenoconazole, followed by azoxystrobin and mancozeb (Fig. 9).

When cultured onto PDA containing either carbendazim, tebuconazole, or thiophanate-methyl, the conidial germination of A. caulina was slightly malformed, with slight swellings at the base or tip of the germ tube (Fig. 10A, B, and E). When cultured for $12 \mathrm{~h}$ on PDA containing either azoxystrobin or mancozeb, conidial germination was severely malformed, with an altered mode of conidial germination, whereby the germ tubes emerged from two or more sites on the conidia and swollen or more heavily branched bases or tips of the germ tubes (Fig. 10F and G). When cultured for $12 \mathrm{~h}$ on PDA containing the fungicides prochloraz or difenoconazole, the spores germinated normally (Fig. 10C and D). On PDA without any fungicide, the shape of the germ tubes was normal, branches rarely appeared, and the germ tubes emerged from both ends or from the central part of the conidia (Fig. 10H).

\section{Discussion}

In recent years, quinoa black stem has been common in quinoa planting areas in Jingle, Ningwu, Wutai, and Shanyin counties of
Shanxi Province, China. A survey among serious quinoa fields in Jingle County, Shanxi Province, revealed that in an environment of 15 to $25^{\circ} \mathrm{C}$ with an $\mathrm{RH}$ of 60 to $80 \%$, quinoa black stem spread very rapidly, and resulted in lodging, leaf yellowing, and leaf shedding within 8 to 10 days. The disease usually appears on the stems at flowering stage and symptoms can progress up to the stage of maturity in Shanxi Province. The present study showed that both high temperatures and low temperatures affected the mycelial growth and conidial germination of A. caulina (Figs. 4 and 5), thereby affecting its pathogenicity (Fig. 6). This also could partly explain why quinoa black stem was more likely to develop under cooler conditions (15 to $25^{\circ} \mathrm{C}, \mathrm{RH}=55 \pm 2 \%$ ).

The teleomorph of A. caulina (teleomorph: Neocamarosporium calvescens) had not been found in the quinoa planting areas in Shanxi Province for three consecutive years, which might indicate that the disease hazard is attributed to anamorphs in those areas. It has been reported that A. caulina can cause leaf spots or stem lesions in eight species of Atriplex and eight species of Chenopodium, but not quinoa (Table 4) (Boerema et al. 1977, 1987; de Gruyter et al. 2009; van der Aa and van Kesteren 1979). Compared with the symptoms in other host species, A. caulina infected quinoa stems with relatively large lesions, being 5.9 to $9.6 \mathrm{~cm}$ in diameter in the Jingle quinoa plantations, which could cause lodging resulting in greater damage (Boerema et al. 1977). In comparison with the stem lesions caused by Ascochyta hyalospora, the quinoa black stem lesions were more likely to develop under cooler conditions $\left(15\right.$ to $25^{\circ} \mathrm{C}, \mathrm{RH}=55 \pm$ $2 \%$ ) (Li et al. 2017). A. hyalospora is $N$. chenopodii and is closely related to $N$. calvescens (A. caulina) (de Gruyter et al. 2013). A. hyalospora can infect quinoa seeds, seedling roots, and hypocotyls, stems, and leaves, resulting in leaf spots and stem lesions (Boerema et al. 1977, 1987; van der Aa and van Kesteren 1979). A. caulina isolates LMHS-3 and LMHS-5 mainly infected quinoa stems (Fig. 7B), but usually they do not infect the roots, seedlings of quinoa, or the stems of C. album and C. bryoniifolium (Fig. 7A and D). The leaves of $C$. album and $C$. bryoniifolium were easily infected and many pycnidia could be produced (Fig. 8). The inoculation revealed that $A$. caulina could infect the leaves of quinoa in the climate chambers and greenhouse (Fig. 8). However, the foliar symptoms observed on detached leaves and plants grown under greenhouse conditions were not typically observed in the Shanxi quinoa plantations. These results suggest that the infections of quinoa leaves might only develop under favorable conditions, and the quinoa leaf spots caused by A. caulina required further investigation.

Table 4. Strains isolated from black stem on quinoa in this study and reference strains of Ascochyta leaf spot or stem lesion on Atriplex spp. and other Chenopodium plants

\begin{tabular}{|c|c|c|c|}
\hline Strain & Host & Substrate & Citation \\
\hline- & Atriplex hortense & Leaf & van der Aa and van Kesteren 1979 \\
\hline- & A. lacinata & & \\
\hline- & A. littoralis & & \\
\hline CBS 246.79 & A. hastata & & \\
\hline- & A. nitens & Living and dying leaf & \\
\hline- & A. patula & Living leaf & \\
\hline CBS 344.78 & A. hastata & Stem & \\
\hline \multicolumn{4}{|l|}{ CBS 343.78} \\
\hline \multicolumn{4}{|l|}{ CBS 787.68} \\
\hline- & A. hortensis & & \\
\hline- & A. oblongifolium & Dying stem & - \\
\hline- & Chenopodium album & Leaf & van der Aa and van Kesteren 1979 \\
\hline- & C. bonus-henricus & & \\
\hline- & C. glaucum & & \\
\hline- & C. hybridum & & \\
\hline- & C. murale & & \\
\hline- & C. viride & Living leaf & \\
\hline- & C. suecicum & Living or dying stem & \\
\hline- & C. vulvaria & Stem & \\
\hline LMHS-3 & C. quinoa & Living stem & This study \\
\hline LMHS-5 & & & \\
\hline
\end{tabular}


Some species in the genus Neocamarosporium (Crous \& Wingfield) are morphologically similar, which poses significant difficulties in the identification of pathogens (Crous et al. 2014; Grum-Grzhimaylo et al. 2016; Papizadeh et al. 2018; Wanasinghe et al. 2017). Historically, fungal taxonomists have used the morphological characteristics of pathogens on their hosts as an important basis for identification. In the present study, the morphology of $A$. caulina on quinoa was directly observed on sections, and it was found that the pycnidia, conidia, and conidiogenous cells of $A$. caulina that were infecting the quinoa were generally consistent with the A. caulina specimens described by Boerema et al. (1987), Ariyawansa et al. (2015), and Wanasinghe et al. (2017), among others. The conidia of the A. caulina isolates LMHS-3 and LMHS-5 that infected the quinoa were slightly shorter than those seen infecting other hosts, such as pigweed (C. album) and hastata orache (Atriplex hastata) (Boerema et al. 1987).

The model strain of A. hyalospora is CBS 206.80. In 2013, de Gruyter et al. systematically studied CBS 206.80 and CBS 246.79, and showed that there were significant differences in the morphology and molecular characteristics of the two isolates and that they were not the same species (de Gruyter et al. 2013). The morphology and molecular sequences of the isolates LMHS-3 and LMHS- 5 were close to CBS 246.79 (Fig. 3). In 2013, Testen et al. reported that Ascochyta leaf spot of quinoa was caused by an Ascochyta sp. in the United States that was most closely related to CBS 432.77 (Testen et al. 2013). The model strain of $N$. calvescens (anamorph: A. caulina) was CBS 246.79. Because CBS 246.79 was similar to CBS 344.78, CBS 432.77, and CBS 523.66, its taxonomic status has been changed (Crous et al. 2014; de Gruyter et al. 2009; Grum-Grzhimaylo et al. 2016; Papizadeh et al. 2018; Wanasinghe et al. 2017). In 2009, de Gruyter et al. identified CBS 246.79 as A. caulina (Pleospora calvescens) through LSU and SSU sequence analysis and considered CBS 246.79 and CBS 344.78 to be the same species (de Gruyter et al. 2009). de Gruyter et al. (2013) used the ACT sequencing analysis to identify CBS 246.79, CBS 344.78, CBS 432.77, and CBS 523.66 as $P$. calvescens, $P$. chenopodii, $P$. halimiones, and $P$. betae, respectively, and distinguished between CBS 246.79 and CBS 344.78 (de Gruyter et al. 2013). In recent years, CBS 246.79, CBS 344.78, CBS 432.77, and CBS 523.66 have been reidentified as $N$. calvescens, $N$. chenopodii, N. obiones, and $N$. betae, respectively, based on the phylogenetics of multiple genes (e.g., LSU, ITS, SSU, rpb2, ACT) (Ariyawansa et al. 2015; Wanasinghe et al. 2017). The LSU sequences of LMHS-3 and LMHS-5 had $100 \%$ homology with those of $N$. chenopodii (CBS 344.78), N. obiones (CBS 432.77), and N. betae (CBS 523.66). Therefore, the LSU sequences cannot be used to distinguish $N$. calvescens from $N$. obiones, $N$. chenopodii, and $N$. betae. Based on the analysis of multiple genes such as LSU, SSU, and ITS, it was found that the LMHS-3 and LMHS-5 clustered in the same branch as N. calvescens from Atriplex hastata (CBS 246.79) with the 100\% bootstrap support rate, and the relationship was closest to $N$. calvescens (Fig. 3). Collectively, the morphological, pathological, and molecular characterizations confirmed $N$. calvescens (anamorph: A. caulina) as the pathogen that causes quinoa black stem (LMHS-3 and LMHS-5). The hosts of the four isolates that have been reported, CBS 344.78, CBS 343.78, CBS 246.79, and CBS 787.68, are the leaves or stems of $A$. hastata (Table 4) (van der Aa and van Kesteren 1979). The present study found for the first time that isolates LMHS-3 and LMHS-5 can infect quinoa (Table 4).

When quinoa black stem incidence is severe, chemical control is essential (Huang et al. 2016). However, the toxicological effects of different types of fungicides differ, and even the toxicological effects of the same types of fungicide can differ among pathogens (Hou et al. 2014; Xu et al. 2016). For example, azoxystrobin has good inhibitory and teratogenic effects on conidia of Alternaria suffruticosae and Cladosporium paeoniae, and a good inhibitory effect on the mycelia of Colletotrichum gloeosporioides, but fewer inhibitory effects on the conidia (Hou et al. 2014; Xu et al. 2016). The present study showed that mancozeb and azoxystrobin had the strongest inhibitory effects on conidia germination in A. caulina, and that these two agents caused malformation of the conidia during germination. The results suggested that mancozeb and azoxystrobin might provide preventive activities to protect quinoa from A. caulina. Tebuconazole and difenoconazole were shown to have the strongest inhibitory effects on the mycelial growth of A. caulina but had little effect on the conidial germination (Fig. 9). This could also partially explain how tebuconazole and difenoconazole might have curative activities to combat this disease.

In conclusion, a novel disease designated as quinoa black stem, which occurred in many Jingle quinoa cultivation regions of Shanxi, China, was characterized and distinguished from other known Ascochyta leaf spot diseases in this study. Using morphological characteristics and phylogenetic relationships, the causal agent was identified as A. caulina and a newly described pathogen of quinoa black stem. A. caulina isolates LMHS-3 and LMHS-5 were the first isolates that primarily infected quinoa stems and usually did not infect the roots and seedlings of quinoa. Our results can help improve the recognition, diagnosis, and management of this important disease. In the future, surveys of this pathogen are needed to assess its genetic diversity and to elucidate its areas of endemism, host range, infection mechanisms, and epidemiology, so that proactive measures can be taken to combat it.

\section{Literature Cited}

Ariyawansa, H. A., Thambugala, K. M., Manamgoda, D. S., Jayawardena, R., Camporesi, E., Boonmee, S., Wanasinghe, D. N., Phookamsak, R., Hongsanan, S., Singtripop, C., Chukeatirote, E., Kang, J. C., Jones, E. B. G., and Hyde, K. D. 2015. Towards a natural classification and backbone tree for Pleosporaceae. Fungal Divers. 71:85-139.

Bai, Q., Zhai, L., Chen, X., Hong, N., Xu, W., and Wang, G. 2015. Biological and molecular characterization of five Phomopsis species associated with pear shoo canker in China. Plant Dis. 99:1704-1712.

Boerema, G. H., Loerakker, W. M., and Hamers, M. E. C. 1987. Check-list for scientific names of common parasitic fungi. Supplement Series 2a (additions and corrections): Fungi on field crops: Beet and potato; caraway, flax and oil-seed poppy. Neth. J. Pl. Path. 93 (S1):1-20.

Boerema, G. H., Mathur, S. B., and Neergaard, P. 1977. Ascochyta hyalospora (Cooke \& Ell.) comb. nov. in seeds of Chenopodium quinoa. Neth. J. Pl. Path. 83:153-159.

Crous, P. W., Shivas, R. G., Quaedvlieg, W., van der Bank, M., Zhang, Y., Summerell, B. A., Guarro, J., Wingfield, M. J., et al. 2014. Fungal Planet description sheets: 214-280. Persoonia - Mol. Phylogeny Evol. Fungi 32: 184-306.

de Gruyter, J., Aveskamp, M. M., Woudenberg, J. H. C., Verkley, G. J. M., Groenewald, J. Z., and Crous, P. W. 2009. Molecular phylogeny of Phoma and allied anamorph genera: Towards a reclassification of the Phoma complex. Mycol. Res. 113:508-519.

de Gruyter, J., Woudenberg, J. H. C., Aveskamp, M. M., Verkley, G. J. M., Groenewald, J. Z., and Crous, P. W. 2013. Redisposition of phoma-like anamorphs in Pleosporales. Stud. Mycol. 75:1-36.

Dřímalková, M. 2003. Mycoflora of Chenopodium quinoa Willd. Seeds. Plant Prot. Sci. 39:146-150.

Grum-Grzhimaylo, A. A., Georgieva, M. L., Bondarenko, S. A., Debets, A. J. M., and Bilanenko, E. N. 2016. On the diversity of fungi from soda soils. Fungal Divers. 76:27-74

Hou, Y., Xu, J. Q., Song, Y. Z., Hu, J. G., Du, S. F., and Kang, Y. B. 2014. Effects of carbendazim, difenoconazole and azoxystrobin on mycelia growth and conidial germination of Alternaria suffruticosae. J. Plant Prot. 41:367-372.

Huang, Y. F., Wang, H. C., Chen, Q. Y., Wang, J., Zhang, C. Q., and Lu, H. X 2016. Inhibitory activities of six fungicides against mycelial growth and conidial germination of Alternaria alternata. Chin. J. Pestic. Sci. 18:263-267.

Li, J. H., Zhou, X. Y., Huang, H. L., and Li, G. W. 2017. Diseases characteristic and control measurements for Chenopodium quinoa Willd. Pages 305-308 in: Proceedings of the 2017 International Conference on Energy and Environmental Protection. Atlantis Press.

Lupien, S. L. F., Dugan, M., Ward, K. M., and O'Donnell, K. 2017. Wilt, crown, and root rot of common rose mallow (Hibiscus moscheutos) caused by a novel Fusarium sp. Plant Dis. 101:354-358.

Maughan, P. J., Bonifacio, A., Coleman, C. E., Jellen, E. N., Stevens, M. R., and Fairbanks, D. J. 2007. Quinoa (Chenopodium quinoa). Pages 147-158 in: Pulses, Sugar and Tuber Crops. Genome Mapping and Molecular Breeding in Plants. C. Kole, ed. Vol. 3. Springer, Berlin, Heidelberg.

Papizadeh, M., Wijayawardene, N. N., Amoozegar, M. A., Saba, F., Fazeli, S. A. S., and Hyde, K. D. 2018. Neocamarosporium jorjanensis, $N$ persepolisi, and $N$. solicola spp. nov. (Neocamarosporiaceae, Pleosporales) isolated from saline lakes of Iran indicate the possible halotolerant nature for the genus. Mycol. Prog. 17:661-679.

Pellegrini, M., Lucas-Gonzales, R., Ricci, A., Fontecha, J., Fernández-López, J., Pérez-Álvarez, J. A., and Viuda-Martos, M. 2018. Chemical, fatty acid, polyphenolic profile, techno-functional and antioxidant properties of flours obtained from quinoa (Chenopodium quinoa Willd) seeds. Ind. Crops Prod. 111:38-46. 
Ren, G. X., Yang, X. S., and Yao, Y. 2015. Current situation of quinoa industry in China. Crops 5:1-5 (in Chinese with English abstract).

Singh, S., Singh, R., and Singh, K. V. 2016. Quinoa (Chenopodium quinoa Willd), functional superfood for today's world: A review. World Sci. News 58:84-96.

Sun, G. Y., Zhang, R., Zhang, Z., and Zhang, M. 2003. Isolation of sooty blotch and flyspeck fungi from apple surface by picking up the thalli. Acta Phytopathol. Sin. 35:479-480.

Swofford, D. L. 2003. PAUP* 4.0b10. Phylogenetic analysis using parsimony (* and their methods). Sinauer Associates, Sunderland, MA

Testen, A. L., Mckemy, J. M., and Backman, P. A. 2013. First report of Ascochyta leaf spot of quinoa caused by Ascochyta sp. in the United States. Plant Dis. 97:844.

van der Aa, H. A., and van Kesteren, H. A. 1979. Some pycnidial fungi occurring on Atriplex and Chenopodium. Persoonia 10:267-276.

Wanasinghe, D. N., Hyde, K. D., Jeewon, R., Crous, P. W., Wijayawardene, N. N., Jones, E. B. G., Bhat, D. J., Phillips, A. J. L., Groenewald, J. Z., Dayarathne, M. C., Phukhamsakda, C., Thambugala, K. M., Bulgakov, T. S., Camporesi,
E., Gafforov, Y. S., Mortimer, P. E., and Karunarathna, S. C. 2017. Phylogenetic revision of Camarosporium (Pleosporineae, Dothideomycetes) and allied genera. Stud. Mycol. 87:207-256.

Xu, J. Q., Yan, G. F., Tian, J., Che, Z. P., and Kan, Y. H. 2016. Effects of carbendazim, tebuconazole and azoxystrobin on sporulation and conidial germination of Cladosporium paeoniae causing tree peony red spot. J. Plant Prot. 43:850-857.

Yin, H., Zhou, J. B., Chang, F. J., Lv, H., Gong, L. J., and Zhao, X. J. 2018. Identification of pathogen causing downy mildew of Chenopodium quinoa. Acta Phytopathol. Sin. 48:413-417.

Yin, H., Zhou, J. B., Lv, H., Chang, F. J., Qin, N., Zhai, S. Y., Xing, K., Zhao, F., and Zhao, X. J. 2019. Identification of the pathogen causing Cercospora leaf spot on quinoa. Acta Phytopathol. Sin. 49:408-414.

Zang, R., and Huang, L. L. 2007. Study on the pycindiospore germination of apple tree Valsa canker pathogen. Acta Agric. Boreali-occidentalis Sin. 16: 64-67 